\title{
Intramolecular Hydrogen Bond Activation: Thiourea- Organocatalyzed Enantioselective 1,3-Dipolar Cycloaddition of Salicylaldehyde-Derived Azomethine Ylides with Nitroalkenes
}

\author{
Francisco Esteban, ${ }^{\dagger}$ Wioleta Cieślik, ${ }^{\dagger}$ Enrique M. Arpa, ${ }^{\ddagger}$ Andrea Guerrero-Corella, ${ }^{\dagger}$
}

Sergio Díaz-Tendero, ${ }^{\ddagger, \S, \|}$ Josefina Perles, ${ }^{\perp}{ }^{(0)}$ José A. Fernández-Salas, ${ }^{\dagger}$ Alberto Fraile, ${ }^{*}, \dagger, \S_{(0)}$

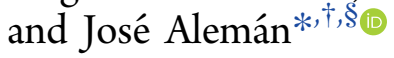

†Departamento de Química Orgánica (Módulo 1), Facultad de Ciencias, Universidad Autónoma de Madrid, 28049 Madrid, Spain

${ }^{\ddagger}$ Departamento de Química (Módulo 13), Facultad de Ciencias, Universidad Autónoma de Madrid, 28049 Madrid, Spain

${ }^{\S}$ Institute for Advanced Research in Chemical Sciences (IAdChem), Universidad Autónoma de Madrid, 28049 Madrid, Spain

"Condensed Matter Physics Center (IFIMAC), Universidad Autónoma de Madrid, 28049 Madrid, Spain

${ }^{\perp}$ X-Ray Diffraction Laboratory, Servicio Interdepartamental de Investigación, Universidad Autónoma de Madrid, 28049 Madrid, Spain

Supporting Information

ABSTRACT: An organocatalytic strategy for the synthesis of tetrasubstituted pyrrolidines with monoactivated azomethine ylides in high enantiomeric excess and excellent exo/endo selectivity is presented. The key to success is the intramolecular activation via hydrogen bonding through an $o$-hydroxy group, which allows the dipolar cycloaddition to take place in the presence of azomethine ylides bearing only one activating group. The intramolecular hydrogen bond in the azomethine ylide and the intermolecular hydrogen bond with the catalyst have been demonstrated by DFT calculations and mechanistic proofs to be crucial for the reaction to proceed.

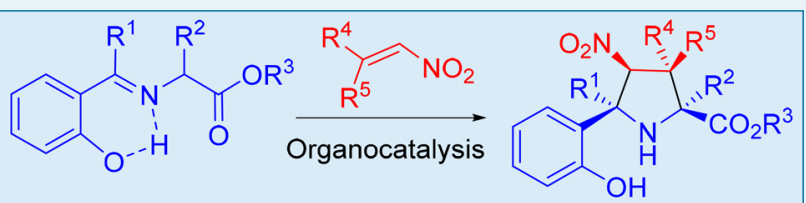

- Organocatalytic, high ee and complete endo selectivity - Only one EWG at the dipole

- Valid for Aldimines and Ketimines

- Valid for $\alpha$-alkyl-substitution and $\beta, \beta$-disubstitution

KEYWORDS: organocatalysis, pyrrolidines, cycloaddition, hydrogen bond activation, thiourea

$\mathrm{T}$ he 1,3-dipolar cycloaddition reaction of azomethine ylides holds a favored position in the synthetic chemist's arsenal to synthesize pyrrolidine derivatives, as it provides one of the most direct and straightforward approaches. ${ }^{1}$ In this area, the preferred strategy involves the use of $\alpha$-amino ester derivatives such as azomethine ylide precursors, since most of the pyrrolidine derivatives present in nature and pharmaceutical products bear a carboxylic acid group at the position $\alpha$ to the nitrogen atom. In the past few years two main approaches have been consolidated in the literature regarding dipolar cycloadditions: metal catalysis ${ }^{2}$ and organocatalysis. ${ }^{3}$ The first one commonly describes a Lewis acid and a weak base combination which promotes the generation of metallo-azomethine ylides (Scheme 1, top). ${ }^{2}$ These metal-catalyzed methods have successfully provided access to a wide range of substituted enantiomerically enriched pyrrolidines. ${ }^{4-9}$

In the past few years, organocatalysis has appeared as a metal-free alternative for the asymmetric synthesis of pyrrolidines via 1,3-dipolar cycloaddition. However, the substitution pattern of the final pyrrolidines that can be prepared is quite restricted. In general terms, this approach needs two activating groups (two EWGs or one EWG and one aryl group) at the dipole $\mathrm{e}^{10-14}$ to increase the acidity of protons in the $\alpha$-position, to overcome the weak activation of the imine
Scheme 1. Different Strategies for the 1,3-Dipolar Reaction with Azomethine Ylides and the Present Work

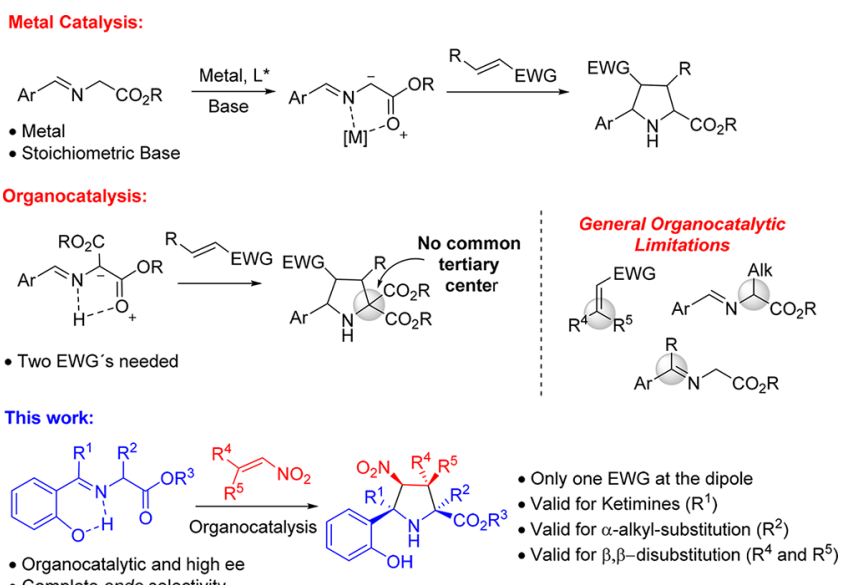

Complete endo selectivity

Received: October 18, 2017

Revised: January 8, 2018

Published: January 31, 2018 
or dipolarophile performed by the organocatalyst (Scheme 1, middle). ${ }^{3}$ Only in a few specific cases, wherein both the imine $\left(p-\mathrm{NO}_{2} \mathrm{C}_{6} \mathrm{H}_{4}\right)$ and the olefin partner (alkyl maleates) are highly activated, the reaction proceeds with a dipole bearing an alkyl and an electron-withdrawing group under $20 \mathrm{~mol} \%$ of phosphoric acid catalysis at $70{ }^{\circ} \mathrm{C} .{ }^{10 j}$ However, to prepare proline scaffolds, which are prevalent in the core structures of efficient catalysts ${ }^{15}$ and biologically important compounds, ${ }^{16}$ would require the cleavage of one of the electron-withdrawing groups (Scheme 1, middle). Moreover, this approach has some additional limitations (Scheme 1, middle-right): (i) there is low reactivity and enantioselectivity with ketimine-dipole derivatives, $^{12}$ (ii) it is unreactive with $\beta, \beta$-disubstituted double bonds, and (iii) no $\alpha$-alkyl substitution is allowed at the dipole. Therefore, it would be highly desirable to develop an organocatalytic method with monoactivated azomethine ylide glycine ester derivatives that would be able to overcome the low reactivity and to solve all the aforementioned limitations described in the literature. In order to reach this objective, we envisioned that an additional activation of the imine, as observed for metal-catalyzed reactions (Lewis base and acid interaction, Scheme 1, top), would be necessary to increase the acidity of the monoactivated azomethine ylides and make it reactive enough in absence of a second activating group. A hydroxy group in the ortho position would be in place to activate the nitrogen of the imine via an intramolecular hydrogen bond (Scheme 1, bottom). This would enhance the acidity of the monoactivated methylene and allow activation by the organocatalyst, which up until now has never been possible. Nitroalkenes were chosen as suitable coupling partners, as they have proved to be activated by bifunctional organocatalysts. Interestingly, the organocatalytic reaction with nitroalkenes as the dipolarophile has scarcely been explored, and only moderate results have been reported. ${ }^{12,14}$

In this work, we describe an organocatalytic method for the synthesis of tetrasubstituted pyrrolidines in high enantiomeric excess and excellent endo selectivity. This strategy employs monoactivated azomethine ylides. A hydrogen bond interaction between the $o$-hydroxy group and the nitrogen of the imine, both present in the dipole, allows the reaction to proceed in the presence of only one activating group (EWG).

Our study started by investigating the dipolar cycloaddition reaction of the azomethine ylides $(\mathbf{1} \mathbf{a}, \mathbf{b})$ and nitroalkene $\mathbf{2 A}$ as model substrates in the presence of a variety of thiourea- and squaramide-based bifunctional catalysts (4) at room temperature (Table 1). As expected, the reaction of azomethine ylide 1a did not proceed $(\mathrm{R}=\mathrm{H}$, entry 1$)$, and we only recovered the unaltered starting materials. To our delight, we found that the presence of an $\boldsymbol{o}$-hydroxy group $(\mathbf{1} \mathbf{b}, \mathrm{R}=\mathrm{OH})$ provoked a dramatic change in the reactivity with good conversions and excellent enantioselectivies, and different thiourea-based catalysts (entries 2-4) could be used. The use of squaramide-based catalysts resulted in lower enantioselectivies and conversions (4d,e) (entries 5 and 6). Takemoto's catalyst 4a (entry 2) was found to be the optimal bifunctional organocatalyst. We then studied the role of the solvent (entries 7-12). The chlorinated (entries 7-9) as well as the oxygenated solvents ( $\mathrm{THF}$ and $\mathrm{Et}_{2} \mathrm{O}$ ), led to the formation of pyrrolidine $3 \mathrm{Ab}$ with lower ee values. When another apolar solvent such as $p$-xylene was used, an excellent conversion and complete endo selectivity (only the endo adduct was observed in all cases) and stereocontrol were observed (entry 12). We tried to decrease the amount of the catalyst loading to $2.5 \mathrm{~mol} \%$. However, low
Table 1. Catalyst Screening and Optimization of the Reaction Conditions ${ }^{a}$

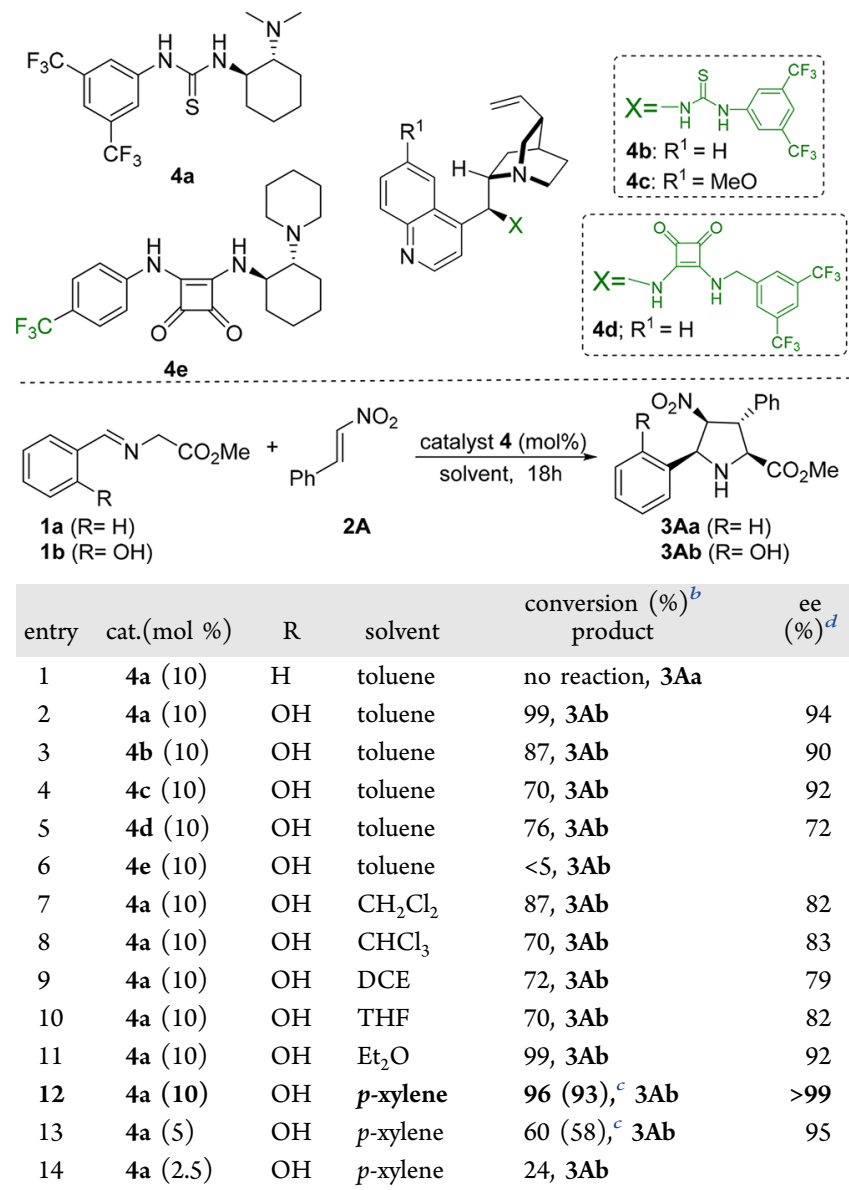

${ }^{a}$ All of the reactions were performed on a $0.2 \mathrm{mmol}$ scale of 1 using dry solvent $(0.2 \mathrm{~mL}) .{ }^{b}$ Determined by ${ }^{1} \mathrm{H}$ NMR analysis of the crude mixture. ${ }^{c}$ Isolated yield after flash chromatography in parentheses. ${ }^{d}$ Determined by SFC.

conversions were found under these reaction conditions (entries 13 and 14).

Once the optimal reaction conditions had been determined (entry 12, Table 1), we studied the scope of the dipolar cycloaddition reaction with regard to the nitroalkene (Table 2). The reaction was scaled up to $2.0 \mathrm{mmol}$, with no detrimental effect on the enantioselectivity (entry 2). Electron-donating groups (3B,C, entries 3 and 4), halogens (3D, entry 5), ortho substituents (3E, entry 6), more sterically hindered aromatic groups (naphthyl group, entry 7), and heterocycles (entry 8) were well tolerated, leading to the desired pyrrolidines with excellent yields and from moderate to excellent enantioselectivities (up to $>99 \%$ ). It is important to note that to date only moderate and low enantioselectivities have been described regarding dipolar cycloadditions of azomethine ylides bearing EWGs with nitroalkenes as coupling partners. ${ }^{12,14}$ The reaction also proceeded with excellent ee values in the presence of a conjugated double bond ( $3 \mathrm{H}$, entry 9$)$ as well as primary (3I), secondary (3J), and tertiary alkyl residues (3K) (entries 1012). However, longer reaction times were required. The more challenging $\beta, \beta$-disubstituted nitroalkene ${ }^{9}$ reacted efficiently with $\mathbf{1 b}$ and led to the pyrrolidine $3 \mathbf{L b}$ with a good yield and enantioselectivity (entry 13). The absolute configuration of the asymmetric centers of $3 \mathrm{Db}$ was unequivocally assigned as $2 R$, 
Table 2. 1,3-Dipolar Cycloaddition of Nitroalkenes 2 with $1 \mathrm{~b}$ under Bifunctional Catalyst $4 \mathrm{a}^{a}$

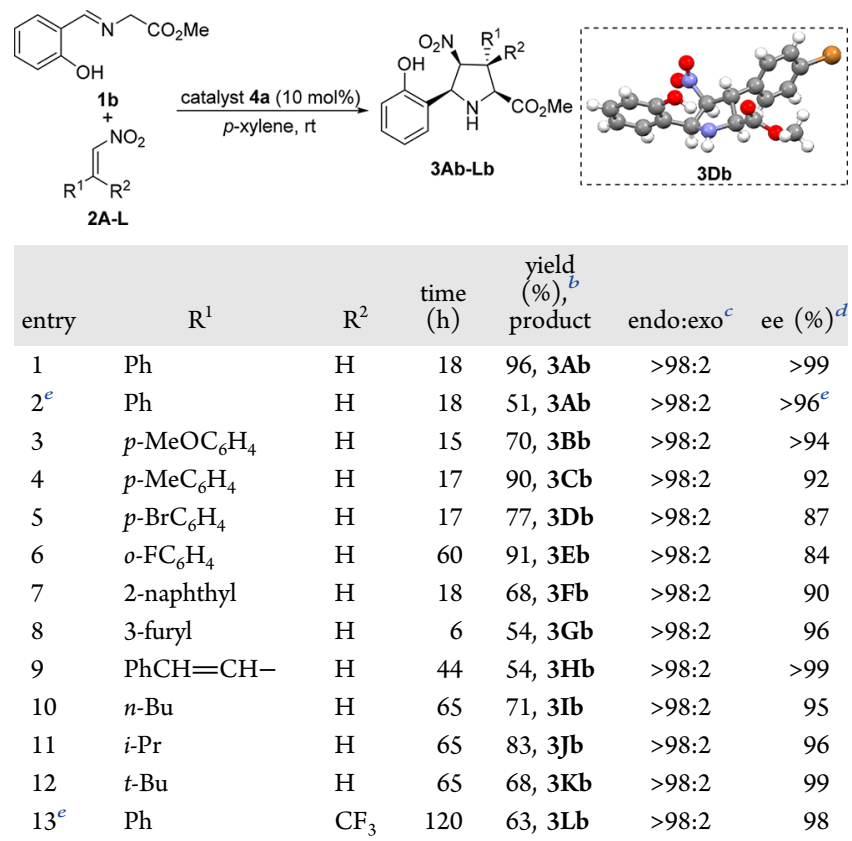

${ }^{a}$ All of the reactions were performed on a $0.2 \mathrm{mmol}$ scale of $\mathbf{1 b}$ in 0.2 $\mathrm{mL}$ of $p$-xylene. ${ }^{b}$ Isolated yield after flash chromatography. ${ }^{c}$ Determined by ${ }^{1} \mathrm{H}$ NMR analysis of the crude mixture. ${ }^{d}$ Determined by SFC. ${ }^{e}$ This reaction was carried out on a $2.0 \mathrm{mmol}$ scale using 20 mol $\%$ of catalyst $\mathbf{4 a}$.

$3 S, 4 R$, and $5 S$ (Table 2, top right) by X-ray crystallographic analysis. ${ }^{17}$

A variety of different dipoles $\mathbf{1} \mathbf{c}-\mathbf{i}$ were also studied (Scheme 2). An EWG or EDG at the aryl group of the dipole was tolerated and led to pyrrolidines 3Ac-Ae with excellent enantioselectivities (Scheme 2a). The reaction also worked with 1- and 2-naphthyl derivatives (see Scheme 2b,c). Therefore, when the cycloaddition was carried out with the 2-naphthylimine 1f, the corresponding adduct 3Af was obtained in good yield and high enantioselective excess (Scheme $2 \mathrm{~b}$ ). However, the use of the 1-naphthyl derivative $1 \mathrm{~g}$ afforded the pyrrolidine $\mathbf{3 A g}$ in moderate yield and moderate enantioselectivity (Scheme $2 \mathrm{c}$ ). The reaction also worked at the tertiary center of the dipole $(\mathbf{l h})$, leading to the synthesis of the pyrrolidine $3 \mathrm{Ah}$ with a quaternary center with $79 \%$ yield and excellent ee ( $96 \%$ ee; Scheme $2 \mathrm{~d}$ ). Interestingly, the reaction proceeded with the bulkier and enolizable ketimine ylide $\mathbf{1 i}$ to give pyrrolidines $3 \mathbf{B i}$ and $3 \mathbf{K i}$, bearing a quaternary benzylic center, with excellent enantioselectivities (Scheme 2e). The activation of the aza-methylene ylide by other groups, instead of the hydroxyl group $\left(\mathrm{NH}_{2}\right)$, was also studied with unexpected results. ${ }^{18}$

The $o$-hydroxy group has been demonstrated to be the key to the success of the dipolar cycloaddition. Moreover, we wanted to take advantage of its presence and form valuable building blocks for organic synthesis. We envisioned the formation of the 3,4-dihydrocoumarin scaffold fused to the pyrrolidine ring via a double annulative process, displacing the phosphonate group intramolecularly. ${ }^{19}$ We were delighted to find that ketimines $\mathbf{1} \mathbf{i}, \mathbf{j}$, in the presence of $\beta, \gamma$-unsaturated $\alpha$ ketophosphonates $\mathbf{5}$, led to the formation of dihydrocoumarins 6 with good yields and from moderate to excellent enantioselectivities, in the presence of only one activating
Scheme 2. Use of Different Dipoles 1c-i under Hydrogen Bond Catalysis

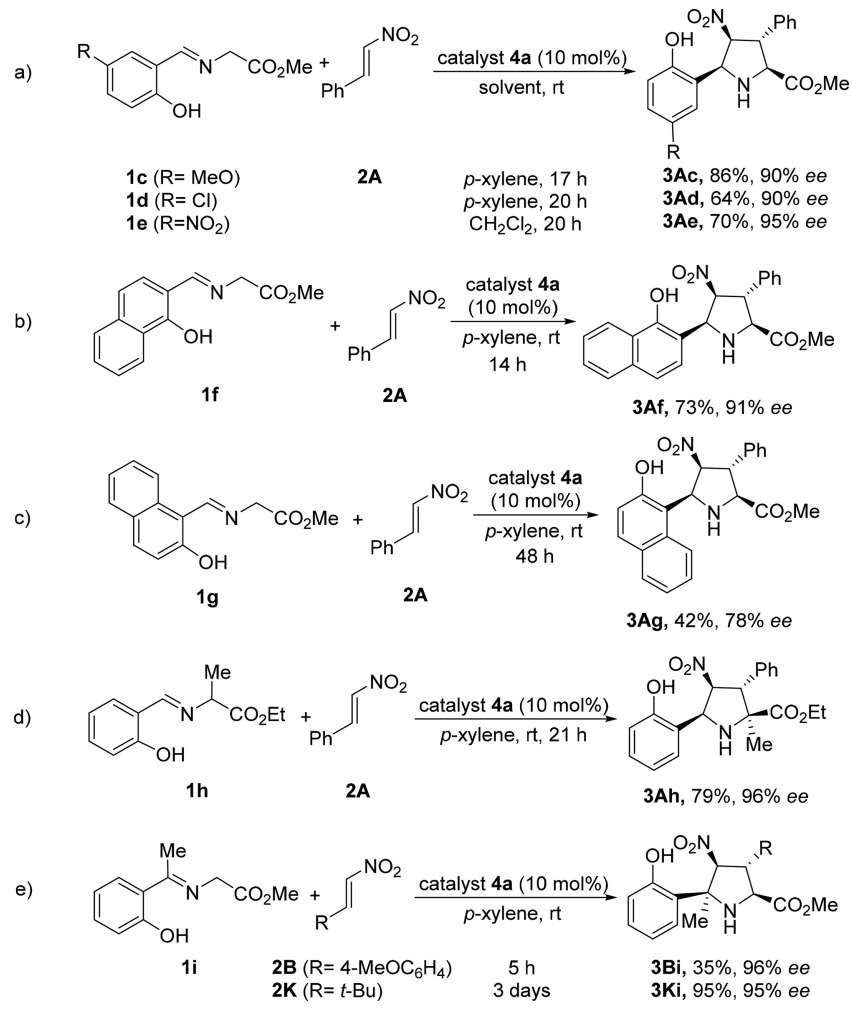

group (Scheme 3). The absolute configuration was determined by X-ray analysis of a crystal from $\mathbf{6} \mathbf{B j} \cdot \mathbf{H C l}$ obtained from protonation of $6 \mathbf{B j}$ with $\mathrm{HCl}$ (see the Supporting Information for details). ${ }^{20}$

In order to gain further insight into the reaction mechanism, additional experiments and DFT calculations were carried out. In our initial hypothesis, the intramolecular hydrogen bond is the key factor in increasing the acidity of the methylene at the imine. The reaction was carried out with the imine $1 a(R=H)$ without any reactivity (entry 1 , Table 1 ). In order to discard any activity as a hydrogen bond acceptor (a Lewis acid), we carried out the reaction with the o-methoxy imine 1 (see Scheme 4a). However, no reactivity was observed after 2 days, due to the absence of an intramolecular hydrogen bond.

Taking into account that the intramolecular hydrogen bond of the hydroxyl group with the imine is necessary to increase the reactivity of the azomethine ylides $\mathbf{1} \mathbf{b}-\mathbf{i}$, we first carried out a conformational study of $\mathbf{1 b}^{\prime}$ by DFT calculations ${ }^{21 a}$ (see Scheme 4, bottom). The NBO analysis of $\mathbf{1} \mathbf{b}^{\prime}$-I shows that the charge associated with the $\mathrm{C}$ atom is -0.311 and that with the $\mathrm{O}$ atom is -0.725 . Isomers $\mathbf{1} \mathbf{b}^{\prime}$-I and $\mathbf{1} \mathbf{b}^{\prime}$-II were the most stable, whereas the suppression of the intramolecular hydrogen bond in conformers $\mathbf{1} \mathbf{b}^{\prime}$-III and $\mathbf{1} \mathbf{b}^{\prime}$-IV provoked an increase in the relative energy of nearly $13 \mathrm{kcal} / \mathrm{mol}$. Moreover, the conformation $1 \mathbf{1 b}^{\prime}$-I possesses the most appropriate orientation for hydrogen bond coordination with the Takemoto's catalyst. The presence of the $\mathrm{OH}$ in imine $\mathbf{l b}$ induces a lower deprotonation energy in comparison with 1a (see Scheme 4b), which could be responsible for the higher reactivity of imine $\mathbf{1} \mathbf{b}$. Precisely, the activation of the azomethine ylide via deprotonation plays a crucial role in the catalytic mechanism (see below). 
Scheme 3. Synthesis of Dihydrocoumarins 6

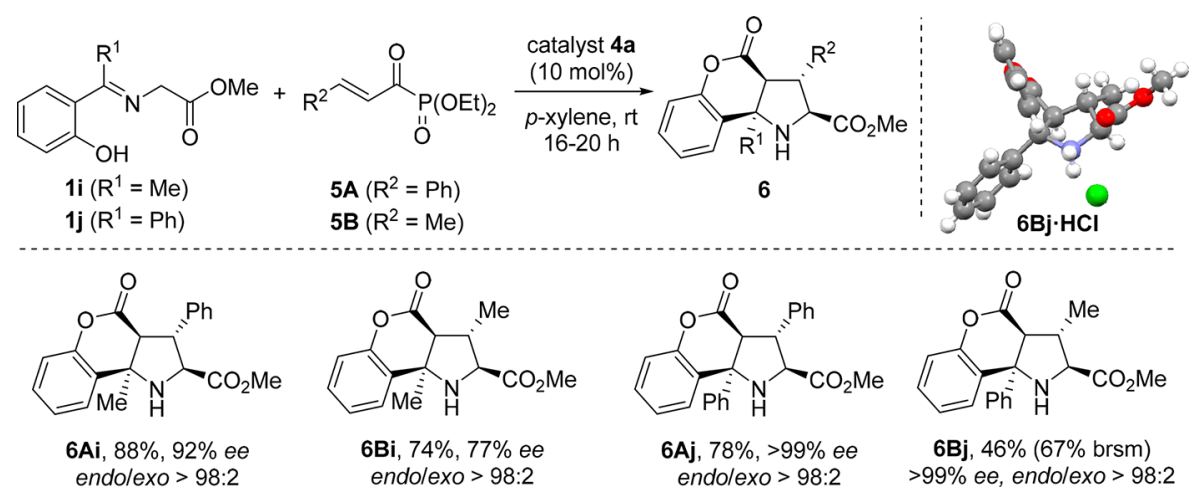

Scheme 4. (a) Reaction of Imine $1 \mathrm{k}$ with $2 \mathrm{~A}$ in the Presence of $4 \mathrm{a}$, (b) Gibbs Free Energy for the Proton Transfer Reaction between Takemoto's Catalyst $4 a$ and Imines 1a,b, and (c) Most Stable Conformations of Imine $1 b^{\prime}$

a)

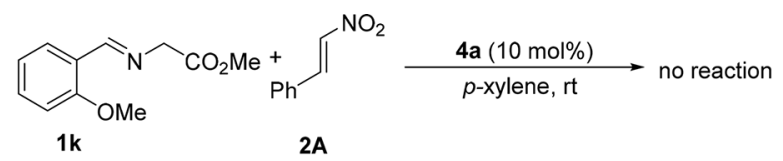

b)
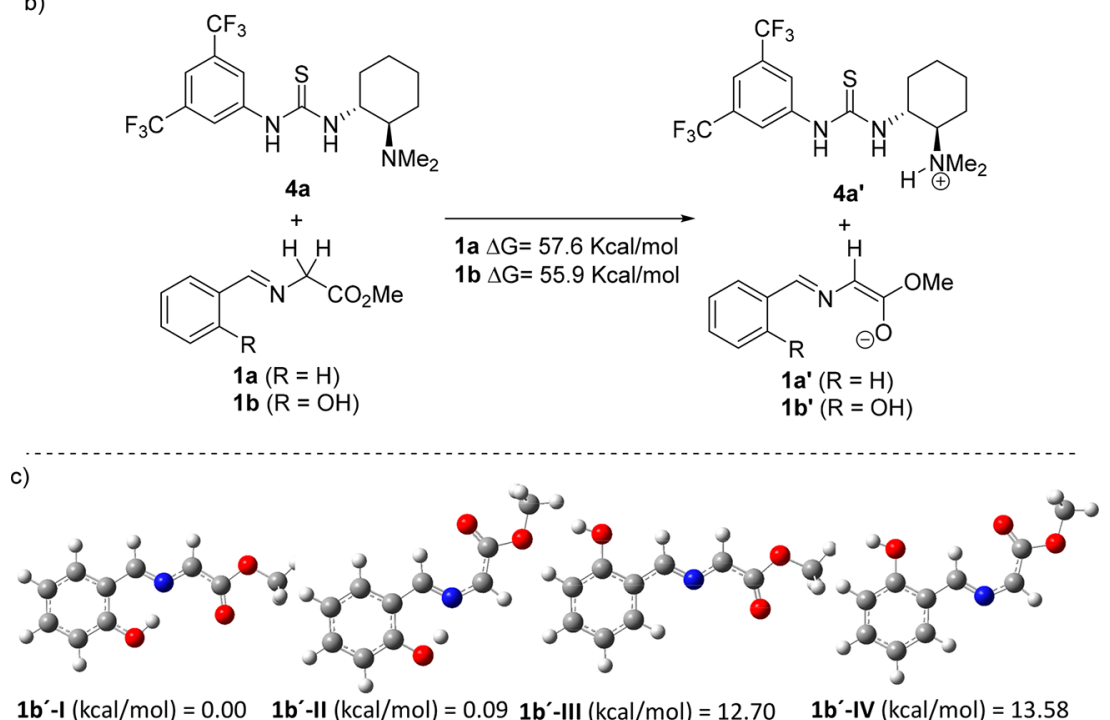

$1 b^{\prime}-I(\mathrm{kcal} / \mathrm{mol})=0.00 \quad 1 b^{\prime}-I I(\mathrm{kcal} / \mathrm{mol})=0.091 \mathbf{b}^{\prime}-$ III $(\mathrm{kcal} / \mathrm{mol})=12.70 \quad 1 \mathbf{b}^{\prime}-\mathrm{IV}(\mathrm{kcal} / \mathrm{mol})=13.58$

We also considered the reaction with the naphthalene-imine $1 \mathrm{~g}$ (see Scheme 2c). This reaction took place after 2 days in $42 \%$ yield with $78 \%$ ee. In this case, a Bader-QTAIM ${ }^{21 b, c}$ analysis indicates the presence of an intramolecular hydrogen bond (see the Supporting Information). Other reasons could be responsible for the lower reactivity at room temperature such as kinetic control, steric effects, and/or intermolecular interactions between catalysts and imine. Therefore, further exploration of the mechanism is needed to understand the role of the intramolecular hydrogen bond of $\mathbf{1 b}$ when it interacts with the catalyst 4a (see below).

We then studied the reaction mechanism of the dipolarophile (nitroalkene) with the azomethine imine $\mathbf{1} \mathbf{b}^{\prime}-\mathbf{I}$ in the presence of catalyst 4a (Figure 1$)^{21}$ by DFT calculations. We considered three different coordination points of the reactants with the catalyst with both endo and exo approaches, considering Takemoto's, ${ }^{22}$ Pápai's, ${ }^{23}$ and Zhong's ${ }^{24}$ models. In each case, the preassociation complex (PAC), ${ }^{25}$ intermediates, and products (still connected to the catalyst) were computed together with the transition states connecting them. While in
Takemoto's model the nitroalkene is directly coordinated to the thiourea moiety, in Pápai's model the thiourea interacts with the azomethine ylide. The third model considered (Zhong), similar to Pápai's model, shows an additional hydrogen bond interaction of the aryl group of the catalyst 4a with the azomethine ylide. First, the geometry and relative energy of the preassociation complex (PAC $)^{25}$ was obtained for the six different approaches. In the case of the exo approaches, low energetic barriers for the first $\mathrm{C}-\mathrm{C}$ bond formation were found $(1.34-2.82 \mathrm{kcal} / \mathrm{mol})$. However, for the second barrier, the intermediates generated for the three different models did not show the proper conformation necessary to form the second $\mathrm{C}-\mathrm{C}$ bond (attack on the $\mathrm{C}=\mathrm{N}$ bond) because the nitronate intermediate was too far away and was not properly oriented (see the Supporting Information for more details). In the case of the endo approaches, the energy for the first barrier ( $\mathrm{TS}^{1}$, first $\mathrm{C}-\mathrm{C}$ bond) from the preassociation complex was also very low once the two reactants (azomethine ylide and nitroalkene) were attached to the catalyst (see Figure 1). Once the first $\mathrm{C}-\mathrm{C}$ bond is formed, the attack on the imine $\left(\mathrm{TS}^{2}\right)$ 


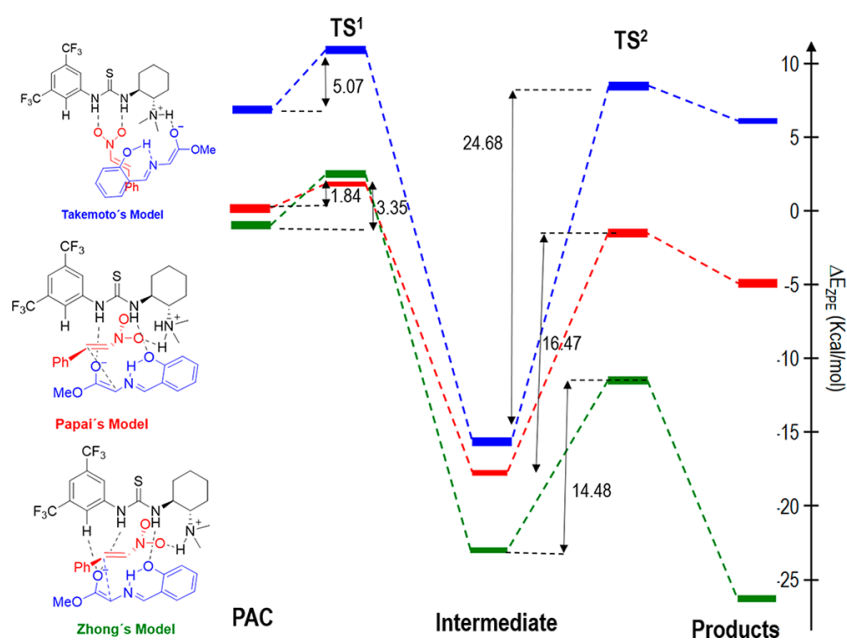

Figure 1. Energetic profile of the endo approaches for the three different models studied (values are in $\mathrm{kcal} / \mathrm{mol}$ ). Relative Gibbs free energies are referenced to the separated reactants $(4 a+1 b+2 A)$. For exo approaches see the Supporting Information.

can take place in the endo approaches, and different energetic barriers were found. Interestingly, Takemoto's model gave the highest energetic barrier $\left(\mathrm{TS}^{2}=24.68 \mathrm{kcal} / \mathrm{mol}\right)$ and led to the opposite enantiomer in comparison with that obtained experimentally, which is a nonplausible mechanism. In the case of Zhong's model while the first barrier $\left(\mathrm{TS}^{1}=3.35 \mathrm{kcal} /\right.$ mol) was found to be higher than in the case of Pápai's model $\left(\mathrm{TS}^{1}=1.84 \mathrm{kcal} / \mathrm{mol}\right)$, the second barrier was found to be lower $\left(\mathrm{TS}^{2}=14.48\right.$ and $16.47 \mathrm{kcal} / \mathrm{mol}$, respectively). In addition, both the intermediate and the product (still attached to the catalyst) found in Zhong's model were thermodynamically more stable. Although both models are possible, the lower kinetic barrier found in Zhong's mechanism makes it the more favorable pathway. Furthermore, the simulations also show that the pathway followed in Zhong's model is the only one whose intermediate lies below the energy of the separate reactants (4a $+\mathbf{1 b}+\mathbf{2 A}$ ), thus confirming the proposed mechanism and assuming this approach.

Bonding Bader analysis in the three PACs shows that an intermolecular hydrogen bond between the thiourea $\mathbf{4 a}$ and the OH group of ylide $\mathbf{1} \mathbf{b}^{\prime}$ is observed only in Zhong's model (see the Supporting Information for further details). For clarity, only the imine part for the three models has been represented in Figure 2 (in Zhong's model the additional hydrogen bond with the catalyst is shown as $\mathbf{4 a - N H}$ ). This additional hydrogen bond provides additional stabilization of the PAC, and it further increases the reactivity of the azomethine ylide (see the Supporting Information). Confirmation of this assumption has been done by a Bader analysis ${ }^{21 b, c}$ on the free imine $\mathbf{1 b}^{\prime}$ and the preassociation complex (PAC) on the three models. Figure 2 presents the electron density in the bond critical point corresponding to the intramolecular $\mathrm{H}$ bond $\left(\rho_{\mathrm{NH}}\right)$, together with the $\mathrm{N}-\mathrm{H}$ and $\mathrm{O}-\mathrm{H}$ distances. In the cases of Pápai's and Takemoto's models, $\rho_{\mathrm{NH}}$ slightly increases from 0.058 to 0.066 and 0.069 , respectively, with respect to the free imine anion $\mathbf{1} \mathbf{b}^{\prime}$, and the N-H bond was shortened by $0.07 \AA$ A Interestingly, in the case of Zhong's model, the presence of the additional intermolecular $\mathrm{H}$ bond between the imine and the catalyst $\mathbf{4 a}$ (see the Supporting Information for the complete Bader analysis) provokes a substantial increase of the strength of the intramolecular $\mathrm{NH}$ bond $\left(\rho_{\mathrm{NH}}=0.082\right)$ and a shorter $\mathrm{N}-\mathrm{H}$

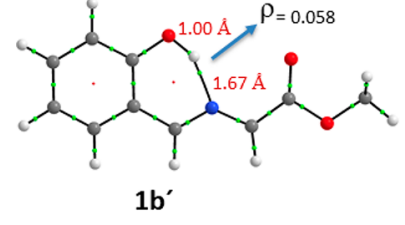

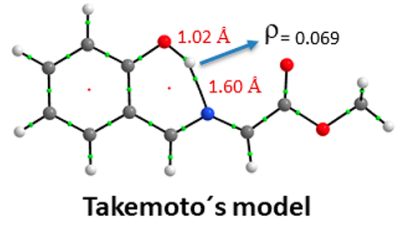

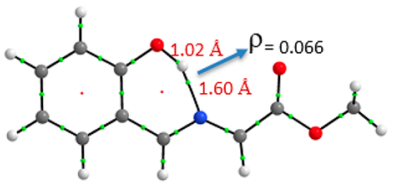

Papai's model

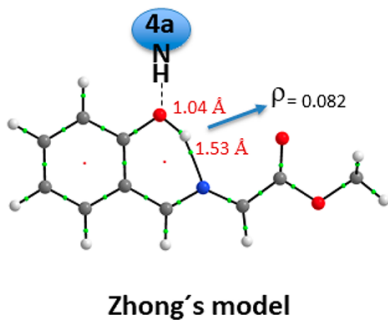

Figure 2. Electron density in the bond critical point and $\mathrm{N}-\mathrm{H}$ and $\mathrm{O}-\mathrm{H}$ distances.

distance (from $1.67 \AA$ in $\mathbf{l b}^{\prime}$ to $1.53 \AA$ in Zhong's model). These consecutive inter- and intramolecular $\mathrm{H}$ bonds are able to stabilize the negative charge $\alpha$ to the carbonyl group and can be considered as one of the main factors favoring Zhong's approach with respect to those of Takemoto and Pápai.

Figure 3 shows the two transition states $\left(\mathrm{TS}^{1}\right.$ and $\left.\mathrm{TS}^{2}\right)$ of Zhong's model. Once the first $\mathrm{C}-\mathrm{C}$ bond (blue line, $3.36 \AA$ ) is
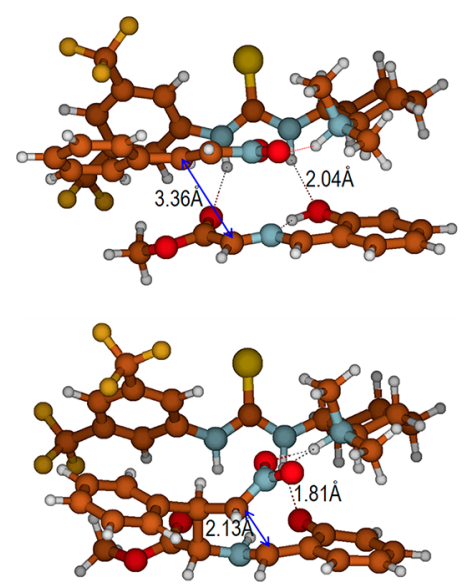

Figure 3. Transition states (top, $\mathrm{TS}^{1}$; bottom, $\mathrm{TS}^{2}$ ) and selected distances for Zhong's model.

formed (top), the nitronate intermediate generated is properly oriented: hydrogen bonds $\left(\begin{array}{ll}1.81 & \AA\end{array}\right)$ between the thiourea moiety and the ammonium, as well as with the hydroxy group, favor the cyclization to form the second $\mathrm{C}-\mathrm{C}$ bond (blue line, $2.13 \AA$ ) to give the final pyrrolidine core.

In summary, an organocatalytic system for the dipolar cycloaddition of monoactivated azomethine ylides using a bifunctional catalyst is presented. The imine-dipole bears an $o$ hydroxy group, which increases the acidity of the methylenic protons and enhances the reactivity, allowing the synthesis of a large variety of pyrrolidines with four contiguous stereocenters with excellent stereocontrol. Therefore, the reaction can be achieved with di- and trisubstituted nitroalkenes, $\alpha$-methyl $\alpha$ amino ester derivatives, and ketimine derivatives as dipolarophiles. This dramatic and crucial increase in the reactivity can be explained by the intramolecular hydrogen bond between the hydroxyl group and the imine at the dipole and the 
intermolecular hydrogen bond with the catalyst $4 a$ which have been experimentally and computationally supported.

\section{ASSOCIATED CONTENT}

\section{S Supporting Information}

The Supporting Information is available free of charge on the ACS Publications website at DOI: 10.1021/acscatal.7b03553.

Experimental details, general procedures, optimization of reaction conditions, characterization of products, NMR and HPLC spectra of all products, X-ray structures, computational details, and theoretical results (PDF) Crystallographic data for 3Db (CIF)

Crystallographic data for $6 \mathrm{Bj}$ (CIF)

Crystallographic data for $\mathbf{6 B j} \cdot \mathbf{H C l}(\mathrm{CIF})$

\section{AUTHOR INFORMATION}

\section{Corresponding Authors}

*A.F.: e-mail, alberto.fraile@uam.es.

*J.A.: e-mail, jose.aleman@uam.es; web, www.uam.es/jose. aleman.

\section{ORCID $\odot$}

Josefina Perles: 0000-0003-0256-0186

Alberto Fraile: 0000-0002-7510-8521

José Alemán: 0000-0003-0164-1777

\section{Author Contributions}

All authors have given approval to the final version of the manuscript.

\section{Notes}

The authors declare no competing financial interest.

\section{ACKNOWLEDGMENTS}

The Spanish Government (CTQ2015-64561-R, CTQ201676061-P) and the European Research Council (ERC-CG, contract number 647550) are acknowledged. We acknowledge the generous allocation of computing time at the CCC (UAM). S.D.-T. gratefully acknowledges the "Ramón y Cajal" program (RYC-2010-07019). Financial support from the Spanish Ministry of Economy and Competitiveness, through the "Maria de Maeztu" Program of Excellence in R\&D (MDM2014-0377), is also acknowledged. F.E. and A.G.-C. thank the Spanish Government for FPI-Ph.D. fellowships and E.M.A acknowledges the Spanish Government for an FPU-Ph.D. fellowship.

\section{REFERENCES}

(1) For general reviews, see: (a) Pandey, G.; Banerjee, P.; Gadre, S. R. Chem. Rev. 2006, 106, 4484-4517. (b) Najera, C.; Sansano, J. M. Top Heterocycl. Chem. 2008, 12, 117-145. (c) Najera, C.; Sansano, J. M. Monatsh. Chem. 2011, 142, 659-680. (d) Adrio, J.; Carretero, J. C. Chem. Commun. 2014, 50, 12434-12446. (e) Narayan, R.; Potowski, M.; Jia, Z. - J.; Antonchick, A. P.; Waldmann, H. Acc. Chem. Res. 2014, 47, 1296-1310. (f) Li, J.; Zhao, H.; Zhang, Y. Synlett 2015, 26, 27452750.

(2) For metallic approaches, see the following review: Adrio, J.; Carretero, J. C. Chem. Commun. 2011, 47, 6784-6794.

(3) For organocatalytic reviews of azomethine ylides, see: (a) Randjelovic, J.; Simic, M.; Tasic, G.; Husinec, S.; Savic, V. Curr. Org. Chem. 2014, 18, 1073-1096. (b) Held, F. E.; Tsogoeva, S. B. Catal. Sci. Technol. 2016, 6, 645-667. (c) Vicario, J. L. Synlett 2016, 27, 1006-1021.

(4) For different EWG groups at the double bond, see: (a) Liu, T. L.; He, Z. - L.; Li, Q. - H.; Tao, H. - Y.; Wang, C. - J. Adv. Synth. Catal. 2011, 353, 1713-1719. (b) González-Esguevillas, M.; Adrio, J.;
Carretero, J. C. Chem. Commun. 2013, 49, 4649-4651. (c) Wang, Z.; Luo, S.; Zhang, S.; Yang, W. - L.; Liu, Y. - Z.; Li, H.; Luo, X.; Deng, W. - P. Chem. - Eur. J. 2013, 19, 6739-6745.

(5) For dipoles bearing different EWG groups, see: (a) Conde, E.; Rivilla, I.; Larumbe, A.; Cossío, F. P. J. Org. Chem. 2015, 80, 1175511767. (b) Gonzalez-Esguevillas, M.; Adrio, J.; Carretero, J. C. Chem. Commun. 2012, 48, 2149-2151. (c) Hernández-Toribio, J.; Padilla, S.; Adrio, J.; Carretero, J. C. Angew. Chem., Int. Ed. 2012, 51, 8854-8858. (d) Robles-Machín, R.; Alonso, I.; Adrio, J.; Carretero, J. C. Chem. Eur. J. 2010, 16, 5286-5291. (e) Yamashita, Y.; Guo, X. - X.; Takashita, R.; Kobayashi, S. J. Am. Chem. Soc. 2010, 132, 3262-3263.

(6) For dipoles bearing heterocycles, see: (a) Pascual-Escudero, A.; Gonzalez-Esguevillas, M.; Padilla, S.; Adrio, J.; Carretero, J. C. Org. Lett. 2014, 16, 2228-2231. (b) Padilla, S.; Tejero, R.; Adrio, J.; Carretero, J. C. Org. Lett. 2010, 12, 5608-5611.

(7) For ketimine dipoles, see: (a) Narayan, R.; Bauer, J. O.; Strohmann, C.; Antonochick, A. P.; Waldmann, H. Angew. Chem., Int. Ed. 2013, 52, 12892-12896. (b) Imae, K.; Konno, T.; Ogata, K.; Fukuzawa, S. - I. Org. Lett. 2012, 14, 4410-4413. (c) Kim, H. Y.; Li, J. - Y.; Kim, S.; Oh, K. J. Am. Chem. Soc. 2011, 133, 20750-20753. (d) Cabrera, S.; Gómez Arrayás, R.; Carretero, J. C. J. Am. Chem. Soc. 2005, 127, 16394-16395.

(8) For $\alpha$-alkyl-substituted dipoles, see: (a) Li, Q. - H.; Liu, T. - L.; Wei, L.; Zhou, X.; Tao, H. - Y.; Wang, C. - J. Chem. Commun. 2013, 49, 9642-9644. (b) Xue, Z. - Y.; Fang, X.; Wang, C. - J. Org. Biomol. Chem. 2011, 9, 3622-3624. (c) Potowski, M.; Schürmann, M.; Preut, H.; Antonchick, A. P.; Waldmann, H. Nat. Chem. Biol. 2012, 8, 428430.

(9) For $\beta, \beta$-disubstituted double bonds, see: Tang, L. - W.; Zhao, B. - J.; Dai, L.; Zhang, M.; Zhou, Z. - M. Chem. - Asian J. 2016, 11, 2470-2477.

(10) For thiourea catalysis, see: (a) Tian, L.; Xu, G. - Q.; Li, Y. - H.; Liang, Y. - M.; Xu, P. - F. Chem. Commun. 2014, 50, 2428-2430. For pyrrolidine catalysis, see: (b) Reboredo, S.; Vicario, J. L.; Badía, D.; Carrillo, L.; Reyes, E. Adv. Synth. Catal. 2011, 353, 3307-3312. (c) Lin, S.; Deiana, L.; Zhao, G. - L.; Sun, J.; Córdova, A. Angew. Chem., Int. Ed. 2011, 50, 7624-7630. (d) Vicario, J. L.; Reboredo, S.; Badía, D.; Carrillo, L. Angew. Chem., Int. Ed. 2007, 46, 5168-5170. For Brønsted acid catalysis, see: (e) Yu, J.; He, L.; Chen, X. - H.; Song, J.; Chen, W. - J.; Gong, L. - Z. Org. Lett. 2009, 11, 4946-4949. (f) Wang, C.; Chen, X. - H.; Zhou, S. - M.; Gong, L. - Z. Chem. Commun. 2010, 46, 1275-1277. (g) Shi, F.; Tao, Z. - L.; Luo, S. W.; Tu, S. - J.; Gong, L. - Z. Chem. - Eur. J. 2012, 18, 6885-6894. For phosphoric acid catalysis, see: (h) Chen, X.-H.; Zhang, W.-Q.; Gong, L.-Z. J. Am. Chem. Soc. 2008, 130, 5652-5653. (i) Chen, X.-H.; Wei, Q.; Luo, S.-W.; Xiao, H.; Gong, L.-Z. J. Am. Chem. Soc. 2009, 131, 13819-13825. (j) He, L.; Chen, X. H.; Wang, D. N.; Luo, S. W.; Zhang, W. Q.; Yu, J.; Ren, L.; Gong, L. Z. J. Am. Chem. Soc. 2011, 133, 13504-13518.

(11) Only very reactive dipolarophiles can react with monoactivated azomethine ylides: (a) Bai, J. - F.; Wang, L. - L.; Peng, L.; Guo, Y. L.; Ming, J. - N.; Wang, F. - Y.; Xu, X. - Y.; Wang, L. - X. Eur. J. Org. Chem. 2011, 2011, 4472-4478. (b) Wang, L.; Shi, X. - M.; Dong, W. - P.; Zhu, L. - P.; Wang, R. Chem. Commun. 2013, 49, 3458-3460.

(12) For ketimine-dipole, see: Xue, M. - X.; Zhang, X. - M.; Gong, L. - Z. Synlett 2008, 2008, 691-694.

(13) (a) Iza, A.; Ugarriza, I.; Uria, U.; Reyes, E.; Carrillo, L.; Vicario, J. L. Tetrahedron 2013, 69, 8878-8884. (b) Reboredo, S.; Reyes, E.; Vicario, J. L.; Badía, D.; Carrillo, L.; de Cózar, A.; Cossío, F. P. Chem. Eur. J. 2012, 18, 7179-7188. (c) Fernández, N.; Carrillo, L.; Vicario, J. L.; Badía, D.; Reyes, E. Chem. Commun. 2011, 47, 12313-12315. (d) Iza, A.; Carrillo, L.; Vicario, J. L.; Badía, D.; Reyes, E.; Martínez, J. I. Org. Biomol. Chem. 2010, 8, 2238-2244.

(14) (a) Xie, J. - W.; Fan, L. - P.; Su, H.; Li, X. - S.; Xu, D. - C. Org. Biomol. Chem. 2010, 8, 2117-2122. (b) Xie, J.; Yoshida, K.; Takasu, K.; Takemoto, Y. Tetrahedron Lett. 2008, 49, 6910-6913. (c) Liu, Y. - K.; Liu, H.; Du, W.; Yue, L.; Chen, Y. - C. Chem. - Eur. J. 2008, 14, 9873-9877. 
(15) (a) Ruiz-Olalla, A.; Retamosa, M.; Cossío, F. P. J. Org. Chem. 2015, 80, 5588-5599. For reviews, see: (b) Mukherjee, S.; Yang, J. W.; Hoffman, S.; List, B. Chem. Rev. 2007, 107, 5471-5569. (c) MacMillan, D. W. C. Nature 2008, 455, 304-308. (d) Albrecht, L.; Jiang, H.; Jørgensen, K. L. Angew. Chem., Int. Ed. 2011, 50, 84928509.

(16) (a) Tripathi, R. P.; Bisht, S. S.; Pandey, V. P.; Pandey, S. K.; Singh, S.; Sinha, S. K.; Chaturvedi, V. Med. Chem. Res. 2011, 20, 15151522. For reviews, see: (b) Felpin, F. - X.; Lebreton, J. Eur. J. Org. Chem. 2003, 2003, 3693-3712. (c) Galliford, C. V.; Scheidt, K. A. Angew. Chem., Int. Ed. 2007, 46, 8748-8758.

(17) CCDC 1524291 (3Db) contains crystallographic data. These data can be obtained free of charge at www.ccdc.cam.ac.uk.

(18) When we performed the reaction with the nitrogen dipole $\mathbf{1 l}$ in the presence of nitroalkene $2 \mathrm{~A}$, we obtained the aza-chromene 7 (see the Supporting Information). This behavior could be justified by the higher nucleophilicity of the nitrogen (11) in comparison to the oxygen (1b).

(19) Kowalczyk, D.; Albrecht, L. J. Org. Chem. 2016, 81, 6800-6807.

(20) CCDC $1588499(6 \mathbf{B j} \cdot \mathbf{H C l})$ and 1549689 (6BJ) contain crystallographic data. These data can be obtained free of charge at www.ccdc.cam.ac.uk.

(21) (a) Geometry optimization was carried out with the M06-2X functional in combination with the $6-31 \mathrm{~g}(\mathrm{~d}, \mathrm{p})$ basis set and including the empirical dispersion correction D3 to include van der Waals forces. Harmonic frequencies and thermodynamic corrections were computed at the same level. More accurate values of the final energy were computed over the geometries previously obtained with the same functional and with the larger basis set $6-31++\mathrm{G}(\mathrm{d}, \mathrm{p})$, including solvent effects ( $p$-xylene) with the SMD solvation model. All simulations were carried out with the Gaussian09 program. See the Supporting Information for more details. For Bader analysis, see: (b) Bader, R. F. W. Atoms in Molecules: A Quantum Theory; Clarendon Press, Oxford, 1990. (c) Bader, R. Chem. Rev. 1991, 91, 893-928.

(22) Okino, T.; Hoashi, Y.; Furukawa, T.; Xu, X.; Takemoto, Y. J. Am. Chem. Soc. 2005, 127, 119-125.

(23) Hamza, A.; Schubert, G.; Sóos, T.; Pápai, I. J. Am. Chem. Soc. 2006, 128, 13151-13160.

(24) Tan, B.; Lu, Y.; Zeng, X.; Chua, P. J.; Zhong, G. Org. Lett. 2010, $12,2682-2685$.

(25) For a study about the importance of preassociated complexes in an aminocatalytic case, see: Arpa, E. M.; Frías, M.; Alvarado, C.; Alemán, J.; Díaz-Tendero, S. J. Mol. Catal. A: Chem. 2016, 423, 308318. 